PAPER

\title{
Nudging, informed consent and bullshit
}

\author{
William Simkulet
}

\section{Correspondence to}

Dr William Simkulet, Philosophy Department, Mid Michigan

Community College, Harrison,

MI 48625, USA;

simkuletwm@yahoo.com

Received 19 July 2017

Revised 22 October 2017

Accepted 31 October 2017

Published Online First

18 November 2017

\section{SLinked}

- http://dx.doi.org/10.1136/ medethics-2017-104317

- http://dx.doi.org/10.1136/ medethics-2017-104653

- http://dx.doi.org/10.1136/ medethics-2017-104654

- http://dx.doi.org/10.1136/ medethics-2018-104833

Check for updates

To cite: Simkulet W.

$J$ Med Ethics

2018:44:536-542.

\section{ABSTRACT}

Some philosophers have argued that during the process of obtaining informed consent, physicians should try to nudge their patients towards consenting to the option the physician believes best, where a nudge is any influence that is expected to predictably alter a person's behaviour without (substantively) restricting her options. Some proponents of nudging even argue that it is a necessary and unavoidable part of securing informed consent. Here I argue that nudging is incompatible with obtaining informed consent. I assume informed consent requires that a physician tells her patient the truth about her options and argue that nudging is incompatible with truth-telling. Instead, nudging satisfies Harry Frankfurt's account of bullshit.

In the wake of medical atrocities in which physicians and researchers disregarded their patients' welfare for personal, professional or scientific gain, contemporary physicians and researchers are said to have a professional moral obligation to obtain informed consent from their patients and/or research subjects before performing medical interventions or medical research on them. For a patient to give genuine informed consent, the patient must be competent and must understand her options and their expected risks and benefits; however, the patient's choice need not be rational.

Although patients might come to understand their medical options in a variety of ways, in most situations patients expect, and are expected to, come to understand them through interacting with their physicians. Patients generally see their physicians as medical experts, and believe that as physicians, they have a professional moral obligation to educate their patients by providing adequate disclosure regarding their patients' medical status and options. Patients expect their physicians to tell them the truth, the whole truth and nothing but the truth.

Patients do not always consent to the medical interventions their physicians recommend. There are many reasons for this, ranging from fear or mistrust to patients simply having different priorities than their physicians or being more intimately familiar with their own goals or limitations than their physicians.

Recently, some philosophers have advocated that physicians nudge their patients towards choosing the physician's preferred option, where a nudge is any influence that is expected to predictably alter a person's behaviour without explicitly forbidding options or substantively changing the target's reasons for acting. ${ }^{1-6}$ Nudges exploit non-rational aspects of patient psychology to persuade patients through means other than rational persuasion. ${ }^{2}$ Some philosophers even contend that nudging is a necessary or unavoidable part of obtaining informed consent. ${ }^{4-7}$ Many philosophers have criticised the practice of nudging in medical contexts, arguing that nudging is unacceptable because it limits or violates patients' autonomy because it is deceptive, coercive, compulsory and/or encourages irrational decision-making. ${ }^{8-16}$

Here I present a different argument against physicians nudging their patients. For a physician to reasonably believe she has received informed consent from her patient, she must first provide that patient with adequate disclosure about treatment options and their expected risks and benefits. This paper will assume, but not argue, that adequate disclosure requires truth-telling. Here I argue that nudging is inconsistent with truth-telling, and thus a physician who nudges does not provide adequate disclosure to her patients, and thus cannot reasonably conclude that she receives genuine informed consent from her patients.

My argument turns on a distinction between truth-telling, lying and a third kind of speech-what Harry Frankfurt calls 'bullshit. ${ }^{17}$ Frankfurt argues that both the truth-teller and the liar are concerned with the meaning of their words; they want their listener to believe what they say is true, while bullshitter doesn't care about whether her audience believes what she says, only that they believe or do something unrelated. Below I argue that a physician who attempts to nudge when securing informed consent fails to provide adequate disclosure, as she is not interested in whether or not her patient understands her options, but only in whether her patient chooses the option she wishes.

This paper is divided into two sections. The first section examines nudging. The second summarises Frankfurt's account of truth-telling, lying and bullshit. Here I argue that nudging is neither truthtelling nor lying, but does count as bullshit.

\section{NUDGING}

Proponents of nudging champion it as a means to predictably alter people's choices without undermining their freedom. Thaler and Sunstein offer the following example of how public servants can improve people's lives without limiting their options:

Cafeteria: Carolyn, the director of food services for a large city school system, takes an interest in improving students' nutrition. Adam, a friend with experience designing supermarket floor plans, proposes rearranging food placement in the cafeteria so that healthier foods are placed at eye level. ${ }^{1}$ 
Thaler and Sunstein contend that in such a case, although the menu has not changed, the change is likely to have a big effect on how often certain foods are consumed. Shlomo Cohen says of this case:

As long as nudging tinkers only with the structure or environment of choice, we can influence the choices made while remaining loyal to libertarianism's ideal of not interfering with the chooser's free actions. If, for example, as a health-promoting measure, we put the healthy foods at eye level at the beginning of the cafeteria shelf, they will be chosen more often and other items less often, although the freedom to pick any item remains unchanged. ${ }^{2}$

Carolyn acts paternalistically in Cafeteria if her action is intended to benefit the children in question. But nudging need not be paternalistic. Supermarkets and drugstores in the USA are infamous for lining checkout lanes with overpriced candy, soda and toys; such behaviour is intended to prompt impulse purchases to increase profit, rather than satisfy their customers' interests. Similarly, if Carolyn were to nudge students to choose healthy foods because she gets a kickback from healthy food companies, her actions cannot charitably be interpreted as paternalistic.

Philosophical support for nudging in medical settings seems limited to nudging done with paternalistic motivations. Proponents argue that physicians have a strong moral obligation to advance the welfare of their patients and see nudging as a means to do so. Because nudging doesn't cut of patient's alternatives, some proponents argue that it does not violate their patients' autonomy, and thus is consistent with informed consent.

However, even if nudging were consistent with obtaining informed consent, it is not clear how reliably observers could distinguish paternalistic nudging from self-serving nudging. Medical supervisors cannot reasonably be expected to distinguish between nudging to benefit the patient and nudging to benefit the physician; just as a self-serving Carolyn might be getting a kickback from healthy food companies, the physician might be getting a kickback from medical companies. A mildly competent physician could take kickbacks from name-brand drug companies and nudge patients towards using name-brand drugs and maintain comparable success rates to their colleagues advocating the generic drug counterparts. Even if there was an investigation of low success rates or higher-than-average patient bills, such physicians could reasonably claim they were only doing as their patients requested.

Nudging can, and likely should, be used in a variety of medical contexts to encourage healthy behaviour; this might range from rewarding patients with financial incentives for getting regular medical exams to prominently displaying relevant medical pamphlets (rather than, say, advertisements) in a waiting room. Dentists have been nudging their patients unabashedly for quite some time, routinely giving out toothbrushes and associated dental amenities to patients after check-ups, scheduling regular check-ups months in advance, sending out reminders of upcoming appointments and the like. Of course, we might quibble about whether dentists should give children lollipops or stickers after a check-up, but generally the vast majority of these nudges can be interpreted as paternalistic.

The context of securing informed consent offers unique challenges to proponents of nudging, as genuine informed consent requires that a patient understand their medical situation, options and the expected costs and benefits of each of their options. This understanding involves awareness, but it seems most nudges work best when they catch their target unaware.
During the process of securing informed consent, either the patient is aware their physician could be nudging or she is not. If she is not, it's not clear that we can interpret her consent as truly informed as she doesn't understand what is going on. However, suppose the patient is aware; if so, her job has become that much harder, as now she is interested in understanding what her physician is saying and why her physician is saying it.

In some respects, physicians' obligations during the process of securing informed consent are herculean. In order to receive genuine informed consent, physicians qua medical experts are tasked to educate distraught patients with a variety of educational backgrounds, interests and levels of trust. Before looking at the prospect of paternalistic nudging during this process, it will be practical to talk about two aspects of adequate disclosure that have been sometimes said to be nudges-recommendations and framing. Here I will briefly argue that appropriate recommendations and framing are part of adequate disclosure because they convey information about a patient's options, the expected risks and rewards of those options and cues for how the patient ought to feel about those things. Nudges aim to alter behaviour through means other than rational discourse, but recommendations and appropriate framing give patients substantive reasons to consider, and thus fail to constitute genuine nudging.

\section{Recommendations}

Often, well before discussing a patient's medical options with her, a physician will have already identified an option she believes best for the patient, where 'best' here is to be understood as facilitating the patient's welfare, with allowances for the patient's interests. There can be sensible debate as to what extent physicians should be concerned with patients' interests beyond their mere biological or psychological health, and there is reason to think that physicians are far less likely to understand a patient's interests than the patient herself; but these topics are outside the scope of this paper.

When the option the physician believes best is far preferable to a patient's other options, adequate disclosure requires the physician to recommend this far preferable option. A physician who recommends an unnecessary treatment to benefit herself financially or professionally, rather than to benefit the patient, does not act as a physician because she does not act with appropriate concern with regard to the patient's well-being, and it doesn't make sense to call this a genuine recommendation.

Some proponents of nudging contend that recommendations are nudges. ${ }^{5}$ After all, patients are more likely to choose the option their physician recommends than other options.

Recommendations are not nudges. Rather, recommendations are often a necessary part of adequate disclosure. Patients see their physicians as medical experts interested in preserving and restoring their health, as such a physician is expected to employ this expertise to benefit their patients medically. If a physician does not recommend one option over another, it might suggest to the patient that one option is just as good as another. If there is a medically significant difference between options, a patient who does not understand this can scarcely be interpreted as understanding their options, and the physician has failed to adequately inform.

Suppose a physician diagnoses her patient with rabies, then informs her patient of her options-(1) treatment by a rabies vaccine, expected to result in her continued life and (2) refraining from treatment, expected to result in her death. The physician is likely to believe (1) is a far better option than (2), such that she does not need to explicitly recommend (1). However, suppose the patient has trouble deciding; the physician should take this 
as evidence that the patient doesn't understand her options! In light of this, the physician should recommend (1) in an effort to adequately inform the patient. A physician that expresses agnosticism regarding whether a patient with rabies ought to get the rabies vaccine fails as a physician.

Of course, a competent patient is free to choose other than the option her physician believes best-whether recommended or otherwise, perhaps motivated by fear, scepticism, misinformation or non-medical concerns like cost and religious beliefs. Recommendations are tools to help clarify difficult-to-understand medical complexities, but if a competent patient can demonstrate that she understands, the physician has good reason to believe she has received genuine informed consent regardless of what the patient chooses.

The reason proponents of nudging mistake recommendations for nudges is that patients are more likely to consent to options that their physicians recommend than those they do not. This is to say that they predictably alter the patients' behaviour. However, by definition, a nudge alters behaviour (a) without altering a patient's options (b) through some means other than rational persuasion. ${ }^{12}$ Appropriate recommendations fail to satisfy criteria (a) and (b).

As patients see their physicians as medical experts interested in their welfare, a recommendation from their physician is a reason to choose that option over other options and it would be hard to call anything a genuine recommendation if the physician didn't believe it best and incoherent to interpret the physician making a recommendation (whether genuine or otherwise) as doing anything other than trying to give their patient a reason to choose that option. As such, recommendations fail to satisfy criterion (b).

A recommendation from a fool is not persuasive. Of course, a physician can abuse her power to make false recommendations, but false recommendations are lies intended to give the audience false beliefs that may influence how they act. If securing informed consent requires truth-telling, false recommendations are obvious at odds with securing informed consent.

A proponent of nudging might argue that recommendations don't change a patient's actual options at all, but rather either their beliefs, feelings or relationship to these options. However, this semantic point is ridiculous; if we take this distinction seriously, then nothing a physician says about a patient's options counts as substantively altering or restricting their options, as it only substantively alters or restricts their perceived options. As such, it seems that recommendations that inform a patient about their options fail to satisfy criterion (a).

One might argue that recommendations can be nudges when they predictably, but inappropriately, influence patients to doing something. After all, many patients trust their physicians qua experts interested in their welfare to recommend what's best, and a physician might recommend one option as it is slightly better than another option, and the patient might misconstrue this as a ringing endorsement that the recommended option is far better. In such a case, though, it is clear the patient doesn't understand. However, let's suppose a physician makes such a recommendation, the patient understands the recommended option is slightly better than the other option, but is psychologically predisposed to be disproportionately enamoured with the recommended option merely because it is recommended. Recommendations are sometimes necessary to secure genuine informed consent, but might predictably lead to irrational behaviour. Are these nudges? The answer depends on the physician's intent. Can a physician intend to recommend to inform and irrationally exploit? These intentions seem mutually exclusive.

\section{Framing}

To secure informed consent, physicians are required to convey information to their patient so that the patient will come to understand her condition. Physicians often have a choice in how they convey this information, and there is substantive evidence that suggests how physicians frame their disclosure can influence how patients act. ${ }^{2} 14$ Cohen characterises framing as a kind of nudge, claiming that a physician can try to influence a patient's decision through choosing non-medical terminology so as to not cause the patient to be anxious. ${ }^{2}$ Blumenthal-Barby and Burroughs note that whether a physician frames a patients' risk in absolute terms or relative terms can reliably change how the patient acts. ${ }^{8}$

As physicians are required to convey information to their patients to secure informed consent, when there is more than one way to frame information, a physician will be required to frame information in one way or another. If this counts as nudging, then nudging is unavoidable when securing informed consent as physicians need to convey information in some way.

However, appropriate framing is not nudging. Those in favour of using frames to persuade patients assume that although multiple frames might convey the same medical information, some frames can convey (or fail to convey) how patients ought to feel. For Cohen, framing can avoid patient anxiety, while Blumenthal-Barby and Burroughs suggest that framing might influence a patient's fear. ${ }^{28}$ Either fear and anxiety are appropriate or they are not. If either is appropriate, and a physician frames disclosure to avoid it, then it doesn't make sense to say that patient understands her options, and thus inappropriate framing fails to satisfy adequate disclosure.

Purposely misleading framing seems to count as lying, as it tries to give patients inaccurate reasons to choose to act, and insofar as it is concerned with giving patients reasons, it cannot be considered nudging.

Once again, let's consider the physician who diagnoses her patient with rabies and informs her of her options. Suppose the physician frames the patient's risks in cuddly language designed not to upset her patient, and this leads the patient to not be (appropriately) concerned with her impending painful death if she does not consent to the vaccine. The patient fails to understand the risks and benefits of her options, so the physician cannot reasonably interpret her patient as giving informed consent. Furthermore, the physician cannot reasonably suggest that she tried to inform her patient if she chose a frame to mislead the patient about the appropriate anxiety or fear she should feel.

Appropriate framing, like appropriate recommending, is consistent with, and often required during, the process of securing informed consent because it helps a patient understand her options, risks and benefits; prerequisites for her making an informed choice.

The reason proponents of nudging sometimes confuse framing for nudging is that they equivocate between a frame's technical meaning and how a patient understands the conveyance; two frames can convey the same technical medical information in two different ways (eg, one might frame it in chances of survival, the other in chances of death), but one frame might reliably cause a patient to be more anxious, fearful or hopeful than the other due to unavoidable emotive and/or non-propositional content that can reasonably be expected to alter behaviour. If this difference is a by-product of patient irrationality, it would be a matter of nudging. If this is the case, then it's not smooth sailing for framing-nudges, as there is some appropriate level of 
anxiety, fear or hope a patient should have in response to a set of information, and if the patient fails to experience the appropriate amount, this is evidence they don't understand and thus cannot give truly informed consent.

Note, however, that proponents of misleading framing cannot reasonably suggest that the patient interprets two frames that elicit different emotional responses differently as conveying the same information; after all they predictably react differently. They may be unable, unwilling or simply uninterested in explaining how the patient misunderstands certain frames, but their difference in reaction just is evidence of a difference in understanding. To assume this is irrational simply because it is unexplained is highly dubious, but in many cases the difference is rational, as one frame emphasises one thing and another doesn't (eg, a frame that conveys information in terms of chance of survival might emphasise survival, while a frame that conveys information in terms of chance of death might emphasise death). Physician emphasis, like physician recommendation, gives patients reasons to act upon, and thus appropriate framing, like recommendations, would give patients reasons to act, rather than influence them irrationally.

\section{Nudging during disclosure}

In 'Nudging and Informed Consent', Cohen proposes a variety of methods in which physicians can attempt to nudge their patients towards their performed option while securing informed consent; here I will summarise his most developed nudging proposal: discouraging disclosure. ${ }^{2}$ Cohen argues that in some situations, physicians should steer patients towards their preferred option by deliberately crafting their disclosure to discourage the patient from continuing to listen. If successful, she will have led the patient to consider only a select portion of the information she would otherwise have disclosed to the patient. He says:

There is rarely an objective measure to the appropriate amount of information the doctor should provide; there is rather a spectrum of reasonableness. Now, within that spectrum, the doctor may legitimately offer the larger amount of relevant information, anticipating it may test the particular patient's patience to listen. A typical reaction by the patient could then be to forgo his or her right to hear more and request the first option presented, provided it is sufficiently good. By explicitly declining further information, the patient allows the doctor to not even present those options the doctor thinks are better not chosen. ${ }^{2}$

Here, nudging involves ordering the disclosed information to annoy the patient, rather than to inform the patient. The physician purports to act as an educator, but chooses their words not to educate, but to annoy. She does not want the patient to come to choose an option through rational deliberation and command of the relevant facts of the situation, but rather because the patient is frustrated by the physician. The physician buries information she doesn't want the patient to understand under trivial information and/or technical terminology (which, in turn, might need to be explained, further obfuscating), hoping the patient will get annoyed and either ask the physician to stop disclosing or merely stop listening to her before the physician gets to the information she believes the patient will find compelling.

Proponents of nudging might contend that the physician has two goals here-educate and nudge. However, this doesn't seem to be the case, as rather than present information in such a way as to encourage the patient to listen and understand or to test the patient to make sure the patient understands, the physician deliberately delivers information to discourage the patient from paying attention. Such actions would be unthinkable in the classroom. Cohen clearly doesn't expect patients on the end of this disclosure to walk away understanding all of their options; instead, he seems content that the patient says that she understands them and waves her right to further disclosure.

\section{BULLSHIT}

In 'On Bullshit', Harry Frankfurt offers an analysis of three kinds of speech-truth-telling, lying and bullshit. ${ }^{17} \mathrm{He}$ begins with classic theories of truth-telling and lying. ${ }^{18-20}$ An agent tells the truth if and only if:

- (1T) $a$ believes $x$.

- (2T) $a$ conveys $x$ to an audience.

- (3 T) $a$ intends the audience to come to believe $x$ (or, at least, that the audience comes to believe that $a$ believes $x$ ).

An agent lies if and only if:

- (1L) $a$ does not believe $x$.

- (2L) a conveys $x$ to an audience.

- (3 L) $a$ intends the audience to come to believe $x$ (or, at least, that the audience comes to believe that $a$ believes $x$ ).

Frankfurt notes that both lying and truth-telling share the same conveyance and intent criteria; what differs is only the agent's belief criterion-the truth-teller believes what she says is true, the liar doesn't. However, Frankfurt contends both are concerned with the truth; the truth-teller to convey it, and the liar to get his audience to believe the lie. Consider the story of the boy who cried wolf:

Wolf: On the first night of his watch, a shepherd boy shouts 'I see a wolf!,' and townsfolk come, prepared to kill a wolf. He saw no wolf and laughs at the townsfolk for believing him. He repeats this for the next few nights, and every time the townsfolk come, there is no wolf, and he laughs at them. On the last night of his watch, the boy really sees a wolf and shouts 'I see a wolf' and nobody comes. The boy is devoured, as are the sheep.

Part of the reason the townsfolk come (at first) is because they believe there is a genuine possibility that the boy sees a wolf. But now consider:

Zombie: On the first night of his watch, a boy shouts 'I see dead people,' but the townsfolk do not come, and the boy is unamused. He saw no dead people and had intended to laugh at the gullible townsfolk, but they weren't as gullible as he had thought. The boy refrains from making false statements for the next few nights. On the last night of his watch, the boy is horrified when he really sees dead people-a horde of zombies shambling closer and ravaging whatever animals they come across. They boy considers shouting 'I see dead people,' but thinks better of it and shouts 'I see a wolf!' The townsfolk come to his aid. The boy and sheep are saved.

Here, 'I see a wolf' is a well-crafted lie-first, it is a claim the townsfolk are likely to believe, and second, although it is deceptive, it is practically so-it will summon townsfolk ready to do battle. Lies, like truths, can be uttered selfishly or selflessly; the boy might lie to save his own skin or to benefit the target audience-the townsfolk.

A liar might lie merely to saddle her target with false beliefs-perhaps the liar enjoys deceiving others; however, often liars intent is to manipulate others by giving them reasons-their newfound false beliefs-to change their behaviour. Similarly, a truth-teller might tell the truth merely to inform her target of true, but trivial facts, but often truth-tellers intend to influence 
their audience by giving them (true) reasons to change their behaviour.

Nudges, too, are meant to influence others, but not through conveying information. Shlomo Cohen contends libertarian paternalism tactics, like nudging, aim 'to influence people through means other than rational persuasion to make choices that are perceived as good for them or even that protect them from themselves. ${ }^{2}$ The nudger doesn't trust the target to be persuaded by rational discourse and seeks to bypass the agent's rational deliberation process to influence the target by exploiting what Yashar Saghai calls her 'shallow cognitive processes', making it more likely she will choose as the physician wants her to rather than what she otherwise would. ${ }^{21}$

Standard adequate disclosure is meant to inform a patient about her options and their expected benefits and risks so that the patient will come to understand them; a prerequisite for the patient's giving genuine informed consent. Nudging isn't designed to do what standard adequate disclosure already does; rather when a physician nudges, she does so to influence the target's choice in some other way than getting her to believe what she says is true. But this just is to say that nudges fail to satisfy either criterion $(3 \mathrm{~T})$ or $(3 \mathrm{~L})$ and thus cannot count as truth-telling or lying.

However, it does satisfy the third part of speech Frankfurt looks at: bullshit. 'One of the most salient features of our culture,' Frankfurt says of bullshit that each of us is confident in our ability to recognise and avoid it. ${ }^{17} \mathrm{He}$ offers the following account of bullshit: an agent bullshits if and only if:

- (1 B) $a$ conveys $x$ to an audience.

- (2 b) $a$ intends the audience to believe some belief (or set of beliefs) $y$ or perform some action (or set of actions) $z$.

While the liar and truth-teller need to be concerned with the truth of what they say, the bullshitter does not. The intent of the bullshitter has nothing to do with the actual meaning of the words she says; she might say ' $x$ ', but she intends her audience to believe $y$ or do $z$, where believing $y$ or doing $z$ does not depend on the audience coming to believe $x$. The bullshitter need not be concerned with the content of her conveyances, only their persuasive power-do they get her audience believe or do what she wants them to do?

Consider the following case:

Book Report: Emily is called to present her report on Of Mice and Men, but forgot to read the book. Believing she will fail the course unless she presents something, she talks about the conflict between the strong and the weak, suggesting the weak are unfairly treated.

Emily doesn't really care if her class or teacher believes what she says is true or even that she read the book. She just wants her teacher to give her a good grade.

When a physician nudges her patient from paternalistic reasons, it may seem as though she tells the truth about the patient's options, but her goal is not to get her patient to understand this information, but rather to nudge the patient towards her preferred option. Thus, it seems nudging is bullshit.

Is it possible to nudge while also telling the truth? Proponents of nudging contend that it is consistent with obtaining informed consent. Genuine informed consent requires adequate disclosure, and by assumption, adequate disclosure requires truth-telling. Thus, for a nudge to be consistent with obtaining informed consent, it must be both truth-telling and bullshit. For a physician's disclosure to count as both adequate disclosure and nudging, it would need to satisfy the following criteria:

- $\left(1 \mathrm{n}^{*}\right) p$ believes $x$.
- $\left(2 \mathrm{n}^{*}\right) p$ conveys $x$ to the patient.

- (3n*a) $p$ intends the patient to come to believe $x$.

- $\left(3 \mathrm{n}^{*} \mathrm{~b}\right) p$ intends the patient to consent to some option $o_{*}$ regardless of her believing $x$.

Consider Cohen's proposal that physicians choose to disclose information in such a way as to annoy their patient into consenting to the option the physician prefers. By stipulation, the physician orders the disclosure so that her patient is likely to refrain from listening to the information being disclosed. In doing so, the physician fails to meet criterion $\left(3 n^{*} a\right)$, and the disclosure cannot constitute truth-telling. It is merely bullshit. Even if the physician utters only true things, by stipulation the physician utters them with the intent that her audience stops listening so that the patient doesn't hear the relevant viable medical options that the physician fears the patient will choose.

\section{Non-propositional conveyances are bullshit}

Proponents of nudging might contend that nudges, in principle, cannot be truth-telling or lying, as they lack propositional content. For example, expressions like 'Yeah!' and 'Boo!' cannot be either true or false; perhaps some nudges share the same lack of true value. Non-propositional conveyances of this kind are frivolous and pointless if they're not designed to influence anyone, and bullshit if they are intended to get a target to do something.

If adequate disclosure involves non-propositional conveyances, one might argue that my assumption that truth-telling requires truth-telling is false, as it is inconsistent with non-propositional conveyances. However, this is a mistake. On Frankfurt's definition of truth-telling, one tells the truth if and only if one conveys $x$, believes $x$ and wants their audience to believe $x$ as well. One can tell the truth about something even if one expects her audience to misinterpret or misunderstand their conveyance; however, for a physician to interpret her patient as giving informed consent, she also has to believe that her audience understands $x$. If a physician tells the truth and the patient doesn't understand, she cannot reasonably interpret this as receiving genuinely informed consent from her patient.

However, this seems to be beside the point. Either the physician chooses to convey $x$ to inform the patient or to nudge them. If the physician chooses the former, even if the patient misunderstands, the physician tells the truth. If the physician chooses the latter, even if the patient comes to understand, the physician bullshits.

Perhaps proponents of nudging can construct a situation wherein the only way a patient can come to understand her situation is if her physician bullshits her. This would be quite an interesting scenario, but I don't think it is a genuine threat to the theory that adequate disclosure requires truth-telling. Students in introductory ethics classes routinely construct scenarios where a physician produces utilitarian benefits by lying to the patient; consider the following:

Introductory Problem Case for Informed Consent: Jones has a rare condition such that she will die if her physician tells her she's sick and will live if her physician tells her she is healthy. She is of no danger to anyone else.

Perhaps in cases such as these, and in cases where understanding requires bullshit, the normal requirement that physicians tell the truth is void. If we were interested in constructing a full conception of the scope and appropriate behaviour of physicians, we might require some foundational principle that usually requires truth-telling during the process of informed consent, 
but sometimes, in these rare cases (which, by their very nature, seem to have to be exceptions to the rule, else they would undermine the patient's willingness to trust the physician at all) lying or bullshit is acceptable. However, this project is outside the scope of this paper and is nothing new.

However, for all intents and purposes, this discussion is irrelevant. The notion that nudging involves genuinely non-propositional conveyances is quite suspect. In discouraging disclosure, the physician orders his disclosure in a particular way to get the patient to choose one of the few options she bothers to listen to. Although this ordering doesn't explicitly say that the early options are better, it clearly implies this.

A competent nudging physician might be able to nonexplicitly imply that some options are better than others simply through ordering them. A physician can only intentionally deceive a patient via ordering if the physician believes the patient will, consciously or otherwise, map value onto the order. Furthermore, outside of some transparently arbitrary ordering (perhaps listing options on pieces of paper drawn at random from a transparent hat), the physician should assume the patient ascribes some relevance to the order (even if this relevance was merely 'of like kind' rather than a value ascription).

Cohen discusses a variety of nudging methods that might be misconstrued as non-propositional, suggesting physicians can choose their mannerisms or attire to influence patients. ${ }^{2}$ However, Scott D. Gelfand notes that this kind of behaviour can have proposition content, implying something like (appropriate or inappropriate) optimism or urgency that can give patients reasons to choose one option over another. ${ }^{22}$ If a physician chooses to dress or act in such a way as to convey such things so that their patient believes them, they tell the truth or lie. When the physician conveys this information, believing it to be true, so that her patient will believe it to be true and act as though it were true, she tells the truth. When the physician conveys this information, believing it to be false, so that her patient will believe it to be true and act as though it were true, she lies in the very same way she might lie if she was to give a false recommendation or misleading frame to persuade her patient.

Proponents of nudging might argue that patients are unaware of any propositional content, but remember that Frankfurt's account of truth-telling, lying and bullshit turns on the speaker's intent, not the audiences' awareness of the speaker's intent.

\section{Gettier-style cases of informed consent}

Gettier-cases are counterexamples to the theory that one has knowledge if and only if one has a justified true belief. ${ }^{23}$ For example:

Little Red: One day Little Red goes to her grandmother's house to deliver baked goods. Her grandmother is feeble and spends most of her day sleeping in her bed. She enters her grandmother's house and sees someone in her grandmother's bed. She hears snoring. She comes to believe that 'My grandmother is home asleep.'

As it so happens, her grandmother was tied up by an anthropomorphic wolf, thrown in the closet and put to sleep using sleeping gas so that she couldn't struggle or make noises. The wolf then dresses in her clothes and hides in her bed, playing a tape recording of Little Red's grandmother's sleeping.

Little Red has a justified true belief; her belief is true because her grandmother is asleep in her closet. However, her belief is justified by unrelated features of the case-the implausible tape recording and the implausible wolf in her grandmother's bed. Thus, although Little Red has a justified true belief, we're inclined to not call it knowledge.
In 'The Gettier Problem in informed consent', Shlomo Cohen discusses cases of informed consent that he says are Gettier-case like; for example:

Gambler: Competent patient Alfred is diagnosed with a cataract in his right eye, and his physician explains his options, their risks and rewards and recommends surgery. A stickler for informed consent, his physician requires Alfred take a written exam, which he passes. His answers are novel and nuanced and better than any textbook, demonstrating his nuanced understanding. However, he refuses treatment and leaves.

Later, Alfred wagers on the outcome of a game; the loser must fulfil one request of the winner. Alfred loses. The winner requests that Alfred get the surgery. Alfred returns to his physician and consents (modified from Cohen's case). ${ }^{24}$

Cohen wonders whether Alfred has given genuine informed consent here, suggesting that the kind of consent Alfred gives is given for the wrong reason.

It is easy to construct a similar case where a patient chooses based off of unintended but unavoidable misconceptions during adequate disclosure:

Foolhardy: Competent patient Bert is diagnosed with a cataract in his right eye. As it so happens, prior to disclosure, his physician came to learn that Bert loves to get surgery. His family explained that he thinks it's brave, and foolhardily opts for any surgeries regardless of context. However, the physician chooses to disclose as normal, explains Bert's options, their risks and rewards and recommends surgery. $\mathrm{He}$ is aware that the term 'surgery' might incline Bert to choose the surgery regardless of all this, but uses it anyway. A stickler for informed consent, his physician requires Bert take a written exam, which he passes. His answers are novel and nuanced and better than any textbook, demonstrating his nuanced understanding. Bert consents to the surgery.

The physician has good reason to believe that Bert's consent is given because of Bert's preconceived notions about surgery rather than for the "right" reasons; however, it does not make sense to say that his physician nudges him, as his physician doesn't choose his disclosure to unduly influence him, even though the undue influence is predictable and perhaps even unavoidable.

This does not constitute bullshit, nor nudging, as the physician does everything he can to tell the truth. We might say that the physician should make it clear that he's aware of Bert's predilections and disapproves of them, but the key feature here is that truth-telling turns on the intent of the conveyor, and informed consent requires only understanding and competency, not that one consents for the right reasons.

Cohen's contention that such cases are relevantly similar to Gettier-cases turns on a confusion, as informed consent does not require a patient make a rational choice, even if a paternalistic physician wishes their patient to make such a choice.

\section{Multitasking}

Suppose that a physician wants to do two unrelated things during the process of securing informed consent-tell the truth about a patient's options and bullshit a patient into choosing an option. Is this acceptable? Perhaps the proponent of nudging contends that one can have two different intentions with a single utterance, to inform and to deceive. I have my doubts that this could be done, but I look forward to proponents of nudging constructing cases meant to satisfy both truth-telling and bullshit at the same time.

That said, I think this enterprise is doomed before it starts because it constitutes multitasking, and multitasking is prima 
facie inconsistent with obtaining informed consent. By assumption, adequate disclosure during the process of securing informed consent requires truth-telling. But consider the following cases:

Juggling: Carol is diagnosed with a cataract in her right eye. Her physician explains her options, their risks and rewards, makes a recommendation and tests Carol, who passes with flying colours. As he does this, he juggles chainsaws because in the off hours he is a chainsaw juggler for a local circus. A professional, he juggles the chainsaws behind a glass divider such that he doesn't risk Carol's life. Carol consents to surgery.

Seduction: Diane is diagnosed with a cataract in her right eye. Her physician explains her options, risks and rewards in a seductive tone, makes a recommendation by whispering it in her ear and tests Diane while reserving a hotel room for what he thinks is a possible post-doctor/patient relationship sexual liaison. Diane passes the test with flying colours. Diane is rather flattered by the attention, but is not sure it is appropriate. Still, she consents to the surgery because he is an expert, resolving to decide whether to report him for sexual harassment and/or consent to his advances after the surgery.

Twin Disclosure: Mary Kate and Ashley are competent conjoined twins diagnosed with brain cancer. Mary Kate is blind and knows English while Ashley is deaf and knows sign language. Their physician knows both spoken English and sign language and chooses to explain their options, risks and rewards simultaneously. After all, he's a busy physician. He recommends surgery to each patient, then tests them. They pass with flying colours. Both consent to the surgery.

These examples are absurd. Although some truth-telling in adequate disclosure may be easy, most involves educating patients about complex issues that they are psychologically and intellectually at a disadvantage to understand. The notion that the physician would juggle chainsaws while expecting his patient to get the same education as though he did not multitask is ridiculous. The behaviour in Seduction is similarly unprofessional. In Twin Disclosure, we might be inclined to think that because both twins are selectively unable to interpret the physician's other behaviour, the disclosure is unproblematic. I think not; the fact of the matter is that in addition to multitasking's unprofessional nature, it also needlessly opens up the possibility of error. No doubt there are people who can successfully text and drive without substantially increasing the chances of getting into an accident, but it seems foolhardy to expend much philosophical ink arguing that professional ambulance drivers have the right to text and drive.

Thus, the proponent of nudging who argues that nudging can be a distinct, and simultaneous, act with truth-telling has two hurdles to overcome-(1) she must be able to construct a scenario where a single action is both intentionally truth-telling and bullshit and (2) argue that the bullshit uncontroversially does not threaten the physician's professional moral obligation to inform her patient. However, either (a) the patient is aware that the physician is nudging or (b) she is not. If (b) she is unaware, it's hard to believe that we can interpret her consent as truly informed because she doesn't know what is going on! However, if (a) she is informed that in addition to telling her the truth her physician might be trying to exploit cognitive weaknesses to predictively coax her to choose a particular option, her job of interpreting her physician's conveyances has become that much harder. If either (a) or (b) is the case, then it seems (2) is false.

\section{CONCLUSION}

In light of this analysis, proponents of nudging have three options:

- Dispute Frankfurt's 3-part theory of truth-telling discussed here.

- Argue genuine informed consent doesn't require truth-telling.

- Argue that nudging is acceptable even if it is inconsistent with informed consent.

None of these options are particularly compelling. Those in favour of option (3) have to explain why a less-than-informed consent consistent with nudging offers sufficient patient protection from potential medical abuses. Option (2) seems to undermine the rationale for requiring informed consent in the first place. Thus, the proponent of nudging must articulate and defend an alternative theory of truth-telling; one that rejects at least criterion (1 T) — that a speaker believes what she says. Such an enterprise, however, would almost certainly itself be bullshit.

Contributor WS is the sole contributor.

Competing interests None declared.

Provenance and peer review Not commissioned; externally peer reviewed.

(c) Article author(s) (or their employer(s) unless otherwise stated in the text of the article) 2018. All rights reserved. No commercial use is permitted unless otherwise expressly granted.

\section{REFERENCES}

1 Thaler R, Sunstein C. Nudge: improving decisions about health, wealth, and happiness. New York, NY: Penguin Books, 2008.

2 Cohen S. Nudging and informed consent. Am J Bioeth 2013;13(6):3-11.

3 Cohen S. Nudging in context: response to open peer commentaries on "nudging and informed consent". Am J Bioeth 2013:13(11):W1-6.

4 Cohen S. A philosophical misunderstanding at the basis of opposition to nudging. Am J Bioeth 2015;15(10):39-41.

5 Douglas C, Proudfoot E. Nudging and the complicated real life of " informed consent". Am J Bioeth 2013;13(6):16-7.

6 Munoz R, Fox M, Gomez M, et al. Evidence-based nudging: best practices in informed consent. Am J Bioeth 2015;15(10):43-5.

7 Brooks T. Should we nudge informed consent? Am J Bioeth 2013;13(6):22-3.

8 Blumenthal-Barby JS, Burroughs H. Seeking better health care outcomes: the ethics of using the "nudge". Am J Bioeth 2012;12(2):1-10.

9 Hansen PG. Should we be "nudging" for cadaveric organ donations? Am J Bioeth 2012;12(2):46-8.

10 Blumenthal-Barby JS. On nudging and informed consent--four key undefended premises. Am J Bioeth 2013:13(6):31-3.

11 Holm S, Ploug T. "Nudging" and informed consent revisited: why "nudging" fails in the clinical context. Am J Bioeth 2013;13(6):29-31.

12 Chwang E. On nudging and informed consent. Am J Bioeth 2015;15(10):41-2.

13 Farrell A-M. Addressing organ shortage: are nudges the way forward? Law Innov Technol 2015;7:253-82.

14 Ploug T, Holm S, Brodersen J, et al. To nudge or not to nudge: cancer screening programmes and the limits of libertarian paternalism. J Epidemiol Community Health 2012;66(12):1193-6.

15 Ploug T, Holm S. Doctors, patients, and nudging in the clinical context--four views on nudging and informed consent. Am J Bioeth 2015;15(10):28-38.

16 Di Nucci E. Habits, nudges, and consent. Am J Bioeth 2013;13(6):27-9.

17 Frankfurt HG. On Bullshit. Raritan 1986;6:81-100.

18 Isenberg A. Deontology and the ethics of lying in aesthetics and theory of criticism: selected essays of Arnold Isenberg. Chicago: University of Chicago Press, 1973:245-63.

19 Primoratz I. Binghamton University State University of New York. Lying and the "methods of ethics". Int Stud Philos 1984;16(3):35-57.

20 Mahon JE. In: Zalta EN, ed. The definition of lying and deception. Stanford: The Stanford Encyclopedia of Philosophy, 2016.

21 Saghai Y. Salvaging the concept of nudge. J Med Ethics 2013;39(8):487-93.

22 Gelfand SD. The meta-nudge-a response to the claim that the use of nudges during the informed consent process is unavoidable. Bioethics 2016;30(8):601-8.

23 Gettier EL. Is justified true belief knowledge? Analysis 1963;23:121-3.

24 Cohen S. The gettier problem in informed consent. J Med Ethics 2011;37(11):642-5. 